\title{
Model Pembelajaran Cooperative Learning Tipe Tebak Kata Terhadap Hasil Belajar Siswa Mata Pelajaran Bahasa Arab di MIN Kemu OKU Selatan
}

\author{
Fera Ferianti \\ Madrasah Ibtidaiyah Al-Awal Baturaja OKU \\ E-mail: fera_ferianti_fe@gmail.com \\ Amir Hamzah \\ Fakultas Ilmu Tarbiyah dan Keguruan \\ Universitas Islam Negeri Raden Fatah Palembang \\ E-Mail: amirhamzah020292@gmail.com
}

\begin{abstract}
Abstrak:
Model pembelajaran Cooperative Learning tipe tebak kata adalah pembelajaran yang menggunakan media kartu teka-teki berpasangan dengan kartu jawaban teka-teki. Tebak kata dapat dijadikan model alternatif untuk mendorong siswa aktif dan belajar bekerjasama dengan pasangannya. Berdasarkan hasil penelitian ini bahwasanya hasil belajar siswa sebelum menggunakan metode Cooperative Learning tipe tebak kata masih sangat rendah. Hal ini dibuktikan dengan siswa yang mendapat nilai tinggi (58 keatas) pre-test sebanyak 5 orang (21,74\%), nilai sedang (37-57) sebanyak 16 orang $(69,56 \%)$, dan nilai rendah (36 kebawah) sebanyak 2 orang $(8,7 \%)$. Dan hasil belajar siswa sesudah diterapkannya model pembelajaran tebak kata yang memperoleh nilai tinggi (98 keatas) sebanyak 8 orang (34,78\%), nilai sedang (88-97) sebanyak 7 orang $(30,44 \%)$ dan mendapatkan nilai rendah (86 kebawah) sebanyak 8 orang $(34,78 \%)$. Hasil uji hipotesis dalam penelitian ini menyatakan Ho tidak terdapat pengaruh dan $\mathrm{Ha}$ menyatakan terdapat pengaruh yang signifikan pada penerapan model pembelajaran Cooperative Learning tipe tebak kata terhadap hasil belajar siswa diterima. Hal ini dapat dilihat dari 2,07 $<17,42>2,82$. Jadi dapat disimpulkan penerapan model pembelajaran Cooperative Learning tipe tebak kata dapat diandalkan sebagai metode yang baik untuk mengajarkan bahasa Arab.
\end{abstract}

Kata Kunci: model tebak kata, hasil belajar

\section{A. Pendahuluan}

Pendidikan merupakan bagian kompleks meliputi berbagai komponen yang terkait satu sama lain, antara lain murid, pendidik, program, pembelajaran, sarana prasarana dan kepemimpinan kepala sekolah (Saipul Annur, 2005, hal. 85-195). Pendidikan merupakan keharusan bagi manusia, terutama bagi umat Islam baik laki-laki maupun perempuan.

Dalam hal ini, masalah pendidikan merupakan masalah yang sangat penting dalam kehidupan, bahkan tidak hanya sangat penting saja, melainkan masalah pendidikan itu sama sekali tidak dapat dipisahkan dari kehidupan. 
Guru dituntut untuk memiliki multi kompetensi agar dapat melakukan tanggungjawabnya dengan baik. Seorang guru dituntut memiliki konsep diri positif, sehingga ia memiliki kepribadian yang mantap dan menjadi teladan dalam kehidupan. Hal tersebut relevan dengan apa yang dikemukakan oleh Qodri bahwa " seorang guru dituntut menciptakan metode baru sekaligus melakukan (creating a moral community in the classroom) menciptakan suatu masyarakat atau kelompok bermoral didalam kelas". (Rusmaini, 2011: 104)

Guru harus memiliki cara mengajar yang tepat agar siswa dapat belajar dengan baik. Guru dengan sadar berusaha mengatur lingkungan belajar agar bergairah bagi siswa. Salah satu usaha yang tidak pernah guru tinggalkan adalah bagaimana memahami kedudukan metode pembelajaran atau model pembelajaran sebagai salah satu komponen yang ikut ambil bagian bagi keberhasilan kegiatan belajar mengajar. Kerangka berfikir yang demikian harus ditanamkan dibenak seorang pendidik (guru).

Seorang guru tentunya akan selalu berharap agar apa-apa yang disampaikan dalam proses pembelajaran akan dapat dimengerti oleh peserta didik secara tuntas. Tentu ini akan menjadi permasalahan yang sulit, dikarenakan masing-masing anak didik mempunyai latar belakang yang berbeda satu sama lain. Seorang guru juga harus mengetahui karakteristik siswa-siswanya. Apalagi masa usia sekolah dasar adalah masa kanak-kanak akhir yang berlangsung dari usia enam hingga kira-kira usia sebelas atau dua belas tahun. sesuai dengan karekteristik anak sekolah dasar yang suka bermain, memiliki rasa ingin tahu yang besar, mudah terpengaruh oleh lingkungan, dan gemar membentuk kelompok sebaya. Oleh karena itu, pembelajaran di sekolah dasar diusahakan untuk terciptanya suasana yang kondusif dan menyenangkan.(Ahmad Susanto, 2012: 86)

Pada umumnya siswa Madrasah Ibtidaiyah cenderung lebih suka bermain dari pada belajar. Mereka lebih suka bergerak aktif dari pada duduk diam dikursi. Siswa Madrasah Ibtidaiyah juga lebih senang jika mereka belajar dalam kelompok-kelompok. Penggunaan model yang sesuai dengan materi dan karakteristik siswa dapat membuat siswa memiliki gairah dan minat belajar, termotivasi, kreatif dalam pembelajaran, dan mencapai tujuan pembelajaran secara optimal. Dengan minat yang berasal dari dalam diri siswa yang merasa senang dan tertarik dengan model yang diterapkan guru, siswa merasa rugi bila tidak mengikuti pelajaran tersebut sehingga ketika kegiatan belajar mengajar berlangsung siswa tersebut akan termotivasi untuk aktif dalam pelajaran dengan menjawab setiap pertanyaan, sehingga hasil yang diperoleh akan optimal. (Rudi Hartono, 2013: 16)

Dari sekian banyak model cooverative learning yang berkembang model tebak kata merupakan salah satu model pembelajaran cooperative learning yang dianggap efektif untuk diterapkan pada pelajaran bahasa Arab. Model tebak kata merupakan model pembelajaran yang berbasis permainan yang sesuai dengan karakter siswa Madrasah Ibtidaiyah yang senang bermain, selain itu model ini sangat sesuai dengan materi alat-alat sekolah 
Salah satu solusi yang dapat dilakukan berdasarkan permasalahan di atas, yaitu dengan menerapkan model pembelajaran Cooperative Learning tipe tebak kata yang merupakan salah satu model pembelajaran yang menekankan kerjasama antara siswa dan guru untuk mencapai tujuan bersama. Model pembelajaran ini juga efektif karena memungkinkan siswa dapat belajar secara optimal, yang pada gilirannya akan dapat meningkatkan hasil belajar siswa.

\section{B. Kerangka Teori}

Model tebak kata adalah pembelajaran yang menggunakan media kartu teka-teki yang berpasangan dengan kartu jawaban teka-teki. Permainan tebak kata dilaksanakan dengan cara siswa menjodohkan kartu soal teka-teki dengan kartu jawaban yang tepat. Tehnik tebak kata menggunakan media kartu atau kertas berukuran $(10 \mathrm{~cm}$ x $10 \mathrm{~cm})$ atau $(5 \mathrm{~cm} \times 10 \mathrm{~cm}$ ) dan tulislah ciri-ciri atau kata-kata yang terkait/ mengarah pada jawaban (istilah) pada kartu yang akan ditebak. Buat kartu yang lebih kecil dengan ukuran $(5 \mathrm{~cm} \times 2 \mathrm{~cm})$ untuk menulis istilah yang akan ditebak. Kartu kecil ini nanti dilipat dan diselipkan ditelinga. (Ridwan Abdullah Sani, 2013: 250)

Langkah-langkah tebak kata

1. Guru menjelaskan kompetensi yang ingin dicapai atau materi kurang lebih 45 menit.

2. Guru menyuruh siswa berdiri berpasang pasangan.

3. Seorang siswa diberi kartu yang berukuran $10 \mathrm{x} 10 \mathrm{~cm}$ yang nanti dibacakan pada pasangannya. Seorang siswa yang lainnya diberi kartu yang berukuran 5 x $2 \mathrm{~cm}$ yang isinya tidak boleh dibaca (dilipat) kemudiaan ditempelkan di dahi atau ditelinga

4. Sementara siswa membawa kartu $10 \times 10 \mathrm{~cm}$ membacakan kata-kata yang tertulis didalamnya sementara pasangannya menebak apa yang dimaksud dalam kartu $10 \mathrm{x}$ $10 \mathrm{~cm}$. Jawaban tepat sesuai dengan isi kartu yang ditempelkan didahi atau telinga.

5. Apabila Jawabannya tepat (sesuai yang ditulis di kartu ) maka pasangan itu boleh duduk. Bila belum tepat pada waktunya yang telah ditetapkan boleh mengarahkan dengan kata-kata lain, asal jangan langsung memberi jawabannya

6. dan seterusnya. (Tukiran Taniredja, 2013: 113)

\section{Kelebihan dan Kekurangan \\ Kelebihannya:}

1. Anak akan mempunyai kekayaan bahasa.

2. Sangat menarik sehingga setiap siswa ingin mencobanya.

3. Siswa menjadi tertarik untuk belajar

4. Memudahkan dalam menanamkan konsep pelajaran dalam ingatan siswa.

Kekurangannya :

1. Memerlukan waktu yang lama sehingga materi sulit tersampaikan.

2. Bila siswa tidak menjawab dengan benar maka tidak semua siswa dapat maju karena waktu terbatas. (Suyatno, 2009: 129) 
Belajar adalah perubahan tingkah laku yang relatif mantap berkat latihan dan pengalaman. Belajar sesungguhnya adalah ciri has manusia dan yang membedakannya dengan binatang. Belajar yang dilakukan oleh manusia merupakan bagian dari hidupnya berlangsung seumur hidup, kapan saja dan di mana saja, baik di sekolah di kelas, di jalanan dalam waktu yang tak dapat ditentukan sebelumnya. (Oemar Hamalik, 2001: 154)

Menurut, Dyimiati dan Mudjiono (1994) hasil belajar adalah tingkat keberhasilan yang dicapai oleh siswa setelah mengikuti suatu kegiatan pembelajaran, di mana tingkat keberhasilan tersebut kemudian ditandai dengan skala nilai berupa huruf atau kata atau simbol.(Fajri Ismail, 2014: 38)

Hasil belajar adalah kemampuan kemampuan yang dimiliki siswa setelah ia menerima pengalaman belajaranya. (Nana Sudjana, 2013: 22) Hasil belajar adalah kompetensi atau kemampuan yang diperoleh peserta didik berkebutuhan khusus setelah melalui kegiatan belajar. (Dedy Kustawan, 2013: 14) Hasil belajar adalah kemampuan yang diperoleh anak setelah melalui kegiatan belajar. (Asep Jihat, 2008: 14)

\section{Hasil Penelitian}

\section{Hasil belajar siswa sebelum (pre-test) penerapan model pembelajaran Cooperative Learning}

Tabel distribusi hasil belajar siswa kelas IV MIN Kemu sebelum diterapkan model pembelajaran Cooperative Learning tipe tebak kata

\begin{tabular}{|c|c|c|c|c|c|}
\hline $\mathrm{X}$ & $\mathrm{F}$ & $\mathrm{Fx}$ & $\begin{array}{c}\mathrm{X} \\
(\mathrm{X}-\mathrm{Mx})\end{array}$ & $\mathrm{x}^{2}$ & $\mathrm{fx}^{2}$ \\
\hline 70 & 2 & 140 & $+22,18$ & 491,95 & 983,9 \\
\hline 60 & 3 & 180 & $+12,18$ & 148,35 & 445,05 \\
\hline 50 & 8 & 400 & $+2,18$ & 4,75 & 38 \\
\hline 40 & 8 & 320 & $-7,82$ & 61,15 & 489.2 \\
\hline 30 & 2 & 60 & $-17,82$ & 317,55 & 635,1 \\
\hline & $\mathrm{N}=23$ & $\sum \mathrm{fx}=1100$ & - & - & $\sum \mathrm{fx}^{2}=2591,25$ \\
\hline
\end{tabular}

Mencari Mean Data :

$$
\begin{aligned}
\mathrm{Mx} & =\frac{\sum \mathrm{fx}}{\mathrm{N}} \\
& =\frac{1100}{23} \\
& =47,82
\end{aligned}
$$

Mencari Standar Deviasi :

$$
\begin{aligned}
\mathrm{SD}_{\mathrm{X}} & =\frac{\sqrt{\Sigma \mathrm{fx}^{2}}}{\mathrm{~N}} \\
& =\frac{\sqrt{2591_{2} 25}}{23} \\
& =\sqrt{112,66} \\
& =10,61
\end{aligned}
$$


Mencari nilai tinggi, sedang dan rendah dengan menggunakan rumus TSR sebagai berikut:

$$
\begin{array}{ll}
\text { Tinggi } & =\mathrm{M}_{\mathrm{X}}+1 \times \mathrm{SDx} \\
& =47,82+1 \times 10,61 \\
& =58,43 \\
& =\text { dibulatkan menjadi } 58 \\
& \text { Jadi, yang termasuk kategori nilai tinggi adalah } 58 \text { keatas } \\
\text { Sedang } & =\mathrm{M}_{\mathrm{X}}-1 \times \mathrm{SDx} \quad \mathrm{S} / \mathrm{d} \quad \mathrm{M}_{\mathrm{X}}+1 \times \mathrm{SDx} \\
& =47,82-1 \times 10,61 \quad \mathrm{~s} / \mathrm{d} \quad 47,82+1 \times 10,61 \\
& =37,21 \quad \quad \mathrm{~s} / \mathrm{d} \quad 58,43 \\
& =\text { dibulatkan menjadi } 37 \text { dan } 58 \\
& \text { Jadi, yang termasuk kategori nilai sedang yaitu antara } 37 \mathrm{~s} / \mathrm{d} 57 \\
& =\mathrm{M}_{\mathrm{X}}-1 \times \mathrm{x} \text { Sx } \\
& =47,82-1 \times 10,61 \\
& =37,21 \\
& =\text { dibulatkan menjadi } 37
\end{array}
$$$$
\begin{array}{rlrl}
\text { Sedang } & =\mathrm{M}_{\mathrm{X}}-1 \times \mathrm{SDx} & \mathrm{s} / \mathrm{d} & \mathrm{M}_{\mathrm{X}}+1 \times \mathrm{SDx} \\
& =47,82-1 \times 10,61 & \mathrm{~s} / \mathrm{d} & 47,82+1 \times 10,61 \\
& =37,21 \quad \mathrm{~s} / \mathrm{d} & 58,43 &
\end{array}
$$

Karena nilai 37 sudah termasuk kedalam kategori nilai sedang. Jadi, nilai 36 kebawah termasuk kategori nilai rendah.

\section{Hasil belajar siswa setelah (post-test 1) penerapan metode ceramah, tanya jawab demonstrasi}

Tabel distribusi hasil belajar siswa kelas IV Madrasah Ibtidaiyah Negeri Kemu setelah diterapkan metode ceramah, tanya jawab dan metode demostrasi

\begin{tabular}{|c|c|c|c|c|c|}
\hline $\mathrm{Y}_{1}$ & $\mathrm{~F}$ & $\mathrm{fY}_{1}$ & $\begin{array}{c}\mathrm{y}_{1} \\
\left(\mathrm{Y}_{1}-\mathrm{My}_{1}\right)\end{array}$ & $\mathrm{y}_{1}{ }^{2}$ & $\mathrm{fy}^{2}$ \\
\hline 100 & 1 & 100 & 31,74 & 1007,42 & 1007,42 \\
\hline 90 & 3 & 270 & 21,74 & 472,62 & 1417,86 \\
\hline 80 & 2 & 160 & 11,74 & 137,82 & 275,64 \\
\hline 70 & 11 & 770 & 1,74 & 3,02 & 33,22 \\
\hline 60 & 2 & 120 & $-8,26$ & 68,22 & 138,44 \\
\hline 50 & 3 & 150 & $-18,26$ & 333,42 & 1000,26 \\
\hline & $\mathrm{N}=23$ & $\sum \mathrm{fy}=1570$ & - & - & $\sum \mathrm{fx}^{2}=$ \\
& & & & & 3872,84 \\
\hline
\end{tabular}

Mencari Mean Data :

$$
\begin{aligned}
\mathrm{My}_{1} & =\frac{\Sigma \mathrm{fy}}{\mathrm{N}} \\
& =\frac{1570}{23} \\
& =68,26
\end{aligned}
$$

Mencari Standar Deviasi : 


$$
\begin{aligned}
\mathrm{SD}_{\mathrm{y} 1} & =\frac{\sqrt{\sum \mathrm{fy}^{2}}}{\mathrm{~N}} \\
& =\frac{\sqrt{3872,84}}{23} \\
& =\sqrt{168,38} \\
& =12,97
\end{aligned}
$$

Mencari nilai tinggi, sedang dan rendah dengan menggunakan rumus TSR sebagai berikut:

$$
\begin{aligned}
& \text { Tinggi }=\mathrm{My}_{1}+1 \times \mathrm{SDy} \\
& =68,26+1 \times 12,97 \\
& =81,23 \\
& =\text { dibulatkan menjadi } 81 \\
& \text { Jadi, yang termasuk kategori nilai tinggi adalah } 81 \text { keatas } \\
& =68,26-1 \times 12,97 \quad \mathrm{~s} / \mathrm{d} \quad 68,26+1 \times 12,97 \\
& =55,29 \quad \mathrm{~s} / \mathrm{d} \quad 81,23 \\
& \text { = dibulatkan menjadi } 55 \mathrm{~s} / \mathrm{d} 81
\end{aligned}
$$$$
\text { Sedang }=\mathrm{My}_{1}-1 \times \text { SDy } \quad \mathrm{s} / \mathrm{d} \quad \mathrm{M}_{\mathrm{y}}+1 \times \mathrm{SDy}
$$

Jadi, yang termasuk kategori nilai sedang yaitu antara $55 \mathrm{~s} / \mathrm{d} 80$

Karena nilai 55 sudah termasuk kedalam nilai sedang. Jadi, nilai 54 kebawah yang termasuk kategori nilai rendah.

\section{Hasil belajar siswa setelah (post-test 2) penerapan model pembelajaran Cooperative Learning tipe tebak}

Tabel distribusi hasil belajar siswa kelas IV Madrasah Ibtidaiyah Negri Kemu setelah diterapkan model pembelajaran Cooperative Learning tipe tebak kata

\begin{tabular}{|c|c|c|c|c|c|}
\hline $\mathrm{Y}_{2}$ & $\mathrm{~F}$ & $\mathrm{fY}_{2}$ & $\begin{array}{c}\mathrm{y}_{2} \\
\left(\mathrm{Y}_{2}-\mathrm{My}\right)\end{array}$ & $\mathrm{y}_{2}{ }^{2}$ & $\mathrm{fy}_{2}{ }^{2}$ \\
\hline 100 & 8 & 800 & $+12,18$ & 148,35 & 1186,8 \\
\hline 90 & 7 & 630 & $+2,18$ & 4,75 & 33,25 \\
\hline 80 & 6 & 480 & $-7,82$ & 61,15 & 366,9 \\
\hline 70 & 2 & 140 & $-17,82$ & 317,55 & 635,1 \\
\hline & $\mathrm{N}=23$ & $\sum \mathrm{fy}_{2}=2050$ & - & - & $\sum_{\mathrm{fy}_{2}}{ }^{2}=2222,05$ \\
\hline
\end{tabular}

Mencari Mean Data :

$$
\begin{aligned}
\mathrm{My}_{2} & =\frac{\Sigma \mathrm{fy}_{2}}{\mathrm{~N}} \\
& =\frac{2050}{23} \\
& =87,82
\end{aligned}
$$


Mencari Standar Deviasi :

$$
\begin{aligned}
\mathrm{SDy}_{2} & =\frac{\sqrt{\Sigma \mathrm{fy}_{2}^{2}}}{\mathrm{~N}} \\
& =\frac{\sqrt{2222,05}}{23} \\
& =\sqrt{96,61} \\
& =9,82
\end{aligned}
$$

Mencari nilai tinggi, sedang dan rendah dengan menggunakan rumus TSR sebagai berikut:

$$
\begin{aligned}
\text { Tinggi } & =\mathrm{My}_{2}+1 \times \mathrm{SDy}_{2} \\
& =87,82+1 \times 9,82 \\
& =97,64 \\
& =\text { dibulatkan menjadi } 98
\end{aligned}
$$

Jadi, yang termasuk kategori nilai tinggi adalah 98 keatas

$$
\begin{array}{rlrr}
\text { Sedang } & =\mathrm{My}_{2}-1 \times \mathrm{SDy}_{2} & \mathrm{~s} / \mathrm{d} & \mathrm{My}_{2}+1+\mathrm{SDy}_{2} \\
& =87,82-1 \times 9,82 \quad \mathrm{~s} / \mathrm{d} & 87,82+1 \times 9,82 \\
& =87,82 \quad \quad \text { s/d } \quad 97,64 & \\
& =\text { dibulatkan menjadi } 88 \mathrm{~s} / \mathrm{d} 98 \\
& \text { Jadi, yang termasuk kategori nilai sedang yaitu } 88 \mathrm{~s} / \mathrm{d} 97
\end{array}
$$

Rendah $\quad=\mathrm{M}_{\mathrm{X}}-1 \times \mathrm{SD}$

$$
=87,82-1 \times 9,82
$$

$=87,82$

$=$ dibulatkan menjadi 88

Karena nilai 88 sudah termasuk kedalam nilai sedang. Jadi, nilai 87 kebawah termasuk kategori nilai rendah

4. Hasil belajar siswa mata pelajaran bahasa Arab pre-test dan post-test 2 yang diterapkannya model pembelajaran Cooperative Learning tipe tebak kata

Hasil belajar siswa di Madrasah Ibtidaiyah Negeri Kemu antara sebelum dan sesudah diterapkan model pembelajaran Cooperative Learning tipe tebak kata.

\begin{tabular}{|c|l|c|c|c|r|}
\hline \multirow{2}{*}{ No } & \multicolumn{1}{|c|}{ Nama } & $\mathrm{X}$ & $\mathrm{Y}_{2}$ & $\mathrm{D}$ & $\mathrm{D}^{2}$ \\
\cline { 3 - 6 } & & Pre-test & Post-test 2 & $\left(\mathrm{X}-\mathrm{Y}_{2}\right)$ & $\left(\mathrm{X}-\mathrm{Y}_{2}\right)^{2}$ \\
\hline 1 & Ahmad Fadli & 50 & 100 & -50 & 2500 \\
\hline 2 & Aisyah Toradia & 50 & 90 & -40 & 1600 \\
\hline 3 & Ali Muzakir Hadi & 60 & 80 & -20 & 400 \\
\hline 4 & Dela Septa Rosa & 40 & 90 & -50 & 2500 \\
\hline 5 & Dimas Anwar & 40 & 100 & -60 & 3600 \\
\hline
\end{tabular}


JIP: Jurnal Ilmiah PGMI

Volume 3, Nomor 2, Desember 2017

\begin{tabular}{|c|l|c|c|c|r|}
\hline 6 & Dinda Safitri & 70 & 100 & -30 & 900 \\
\hline 7 & Galih Naluri Kusuma & 50 & 80 & -30 & 900 \\
\hline 8 & Gita Pare Agustia & 40 & 80 & -40 & 1600 \\
\hline 9 & Huspa Brata Putra & 30 & 70 & -40 & 1600 \\
\hline 10 & Marta Rusmawati & 40 & 100 & -60 & 3600 \\
\hline 11 & M Doni Pirnando & 50 & 100 & -50 & 2500 \\
\hline 12 & Nurazizah & 50 & 90 & -40 & 1600 \\
\hline 13 & Rafli Ardiansyah & 40 & 80 & -40 & 1600 \\
\hline 14 & Rahayu Safitri & 60 & 90 & -30 & 900 \\
\hline 15 & Reko Ezah Pratama & 60 & 100 & -40 & 1600 \\
\hline 16 & Resa Septia & 40 & 90 & -50 & 2500 \\
\hline 17 & M Rizky Agung P & 50 & 100 & -50 & 2500 \\
\hline 18 & Taqia Rahma & 50 & 80 & -30 & 900 \\
\hline 19 & Utia Azaton & 70 & 100 & -30 & 900 \\
\hline 20 & Wita Kristia Ningsih & 40 & 90 & -50 & 2500 \\
\hline 21 & Zikri Pirnanda & 50 & 70 & -20 & 400 \\
\hline 22 & Adelia Natasya & 30 & 80 & -50 & -500 \\
\hline 23 & Indah Pertama Sari & 40 & 90 & & \\
\hline & & & & & \\
\hline
\end{tabular}

a. $\mathrm{M}_{\mathrm{D}}=\sum \frac{\mathrm{D}}{\mathrm{N}}$

$$
\begin{aligned}
& =\frac{-950}{23} \\
& =-41,30
\end{aligned}
$$

b. Mencari Deviasi Standar dari perbedaan antara Skor Variabel I dan skor Variabel II

$$
\mathrm{SD}_{\mathrm{D}}=\sqrt{\frac{\Sigma \mathrm{D}^{2}}{\mathrm{~N}}}-\left[\frac{\Sigma \mathrm{D}}{\mathrm{N}}\right]^{2}
$$




$$
\begin{aligned}
& =\sqrt{\frac{42100}{23}}-\left[\frac{-950}{23}\right]^{2} \\
& =\sqrt{1830,43-(41,30)^{2}} \\
& =\sqrt{1830,43-1705,69} \\
& =\sqrt{124,74} \\
& =11,16
\end{aligned}
$$

c. Mencari Standar Error dengan rumus

$$
\begin{aligned}
\mathrm{SE}_{\mathrm{MD}} & =\frac{\mathrm{SD}_{\mathrm{D}}}{\sqrt{\mathrm{N}-1}} \\
& =\frac{11,16}{\sqrt{23-1}} \\
& =\frac{11,16}{\sqrt{22}} \\
& =\frac{11,16}{4,69} \\
& =2,37
\end{aligned}
$$

d. Mencari " $t$ " atau $t_{0}$

$$
\begin{aligned}
\mathrm{t}_{\mathrm{o}} & =\frac{\mathrm{M}_{\mathrm{D}}}{\mathrm{SE}_{\mathrm{MD}}} \\
& =\frac{-41,30}{2,37} \\
& =-17,42
\end{aligned}
$$

e. Langkah selanjutnya adalah memberikan interpretasi terhadap $t_{\mathrm{o}}$ dengan terlebih dahulu memperhitungkan df atau db-nya: df atau $\mathrm{db}=(\mathrm{N}-1)=23-1=22$

Dengan df sebesar 22, diperoleh harga kritik t pada tabel sebagai berikut :

- Pada taraf signifikan 5\%: $\mathrm{t}_{\mathrm{t}}=2,07$

- Pada taraf signifikan $1 \%: \mathrm{t}_{\mathrm{t}}=2,82$

$$
\longrightarrow \quad 2,07<17,42>2,82
$$

Dengan membandingkan besarnya " $\mathrm{t}$ " yang kita peroleh dalam perhitungan

$\left(\mathrm{t}_{\mathrm{o}}=17,42\right)$ dan besarnya " $\mathrm{t}$ " yang tercantum pada tabel nilai $\mathrm{t}\left(\mathrm{t}_{\mathrm{tabe}} 5 \%=2,07\right.$ dan $\mathrm{t}_{\text {tabel } 1 \%}=2,82$ ). Dengan demikian $\mathrm{t}_{\mathrm{o}}$ lebih besar daripada $\mathrm{t}_{\mathrm{t}}$ baik pada taraf signifikan $5 \%$ maupun taraf signifikan $1 \%$, maka $\mathrm{H}_{\mathrm{O}}$ menyatakan tidak terdapat pengaruh yang signifikan pada penerapan model pembelajaran Cooperative Learning tipe tebak kata pada mata pelajaran bahasa Arab terhadap hasil belajar siswa ditolak. Dan $\mathrm{H}_{\mathrm{a}}$ menyatakan terdapat pengaruh yang signifikan pada penerapan model pembelajaran cooperative learning tipe tebak pada mata pelajaran bahasa Arab kata terhadap hasil belajar siswa diterima.

\section{Kesimpulan}

Penerapan Model pembelajaran cooperative learning tipe tebak kata terhadap hasil belajar siswa mata pelajaran bahasa Arab di MIN 1 Kemu dapat disimpulkan bahwa hasil belajar siswa pada mata pelajaran bahasa Arab materi alat-alat sekolah pada siswa kelas IV sebelum (pre-test) diterapkan model pembelajaran Cooperative 
Learning tipe tebak kata tergolong rendah karena kebanyakan dari 23 siswa mendapat nilai tinggi (58 keatas) sebanyak 5 orang (21,74\%), sedang (37-57) sebanyak 16 orang $(69,56 \%)$ dan rendah (36 kebawah) sebanyak 2 orang $(8,7 \%)$. Hasil belajar siswa setelah (post-test) penerapan metode ceramah, tanya jawab dan demonstrasi nilai tinggi (81 keatas) sebanyak 4 orang (17,39), sedang (55-80) sebanyak 16 orang $(69,57 \%)$ dan rendah (54 kebawah) sebanyak 3 orang (13,04\%). Dan hasil belajar siswa setelah penerapan model pembelajaran Cooperative Learning tipe tebak kata nilai tinggi (98 keatas) sebanyak 8 orang $(34,78 \%)$, sedang (88-97) sebanyak 7 orang $(30,44 \%)$ dan rendah (86 kebawah) sebanyak 8 orang $(34,78 \%)$. Selanjutnya hipotesis nihil yang diajukan dalam penelitian ini ditolak karena $t_{0}$ lebih besar daripada $t_{t}$, yaitu 2,07<

$17,42>2,82$. Ini berarti bahwa terdapat perbedaan nilai hasil belajar siswa pada mata pelajaran bahasa Arab materi alat-alat sekolah kelas IV antara sebelum dan sesudah diterapkannya model pembelajaran Cooperative Learning tipe tebak kata di Madrasah Ibtidaiyah Negeri Kemu merupakan perbedaan yang berarti atau perbedaan yang meyakinkan (signifikan), sehingga secara meyakinkan dapat dikatakan penerapan model pembelajaran Cooperative Learning tipe tebak kata dapat diandalkan sebagai metode yang baik untuk mengajarkan mata pelajaran bahasa Arab materi alat-alat sekolah

\section{Daftar Pustaka}

Abdullah Sani Ridwan. 2013. Inovasi Pembelajaran. Jakarta: Bumi Aksara

Hamalik Oemar. 2001. Perencanaan Pengajaran Berdasarkan Pendekatan Sistem. Bandung: Bumi Aksara

Ismail Fajri. 2014. Evaluasi Pendidikan. Palembang: Tunas Gemilang Press

Jihat Asep dan Abdul Haris. 2008. Evaluasi Pembelajaran. Jakarta: Multi Pressindo

Kustawan Dedy. 2013. Analisis Hasil belajar program perbaikan dan pengayaan peserta didik berkebutuhan khusus. Bandung: Luxima Merto Media

Rusmaini, 2011. Ilmu Pendidikan. Palembang: CV. Grafika Telindo

Sudjana Nana. 2013. Penilaian Hasil Proses Belajar Mengajar. Bandung: PT Remaja Rosdakarya

Suprijono Agus. 2009. Cooperative Learning. Surabaya: Pustaka Pelajar

Susanto Ahmad. 2012. Teori dan Pembelajaran disekolah Dasar. Jakarta: Kencana Prenada Media Group

Suyatno. 2009. Menjelajah Pembelajaran Inovatif. Surabaya: Masmedia Buana Pustaka

Taniredja Tukiran dkk. 2013. Model-model Pembelajaran Inovatif dan Efektif. Bandung: Alfabeta 